\title{
USO DE CORTE POR JATO DE ÁGUA NO DESENVOLVIMENTO DE SUPERFÍCIE TÁCTIL EM ÁGATA A PARTIR DE PADRÃO MODULAR
}

\author{
Flávia Lopes da Silveira \\ UFRGS \\ silveira.f@hotmail.com \\ Wilson Kindlein Júnior \\ UFRGS \\ wilsonkindleinjunior@gmail.com \\ Lauren da Cunha Duarte \\ UFRGS \\ lauren.duarte@ufrgs.br
}

\begin{abstract}
Resumo: Este trabalho tem por objetivo o desenvolvimento de uma superfície táctil a partir de um padrão modular encaixável, visando executá-la em ágata através da usinagem por jato de água. O intuito é gerar uma superfície que possa ser aplicada em painéis de revestimento produzidos em baixa escala de forma semi-industrial. A grande variedade de minerais encontrados no estado do Rio Grande do Sul, a carência de design associado a estes minerais quando do produto final, e o volume de rejeitos proveniente deste beneficiamento, foram os principais motivadores para a utilização da ágata. $O$ estudo de diferentes técnicas de design de superfície irá auxiliar na transformação desta matéria prima, até que a mesma passe a ter o formato de módulo.
\end{abstract}

Palavras-chave: padrão modular, ágata, usinagem por jato de água.

\begin{abstract}
This paper aims the developing a tactile surface from modular plug patterns, aiming to run it in agate with a waterjet machining. The aim is to generate a surface that can be applied in coating panels that can be produced on a semiindustrial small scale. The great variety of minerals found in Rio Grande do Sul State, the lack of design associated to these minerals in its final product and the volume of the waste originated from this processing were the main motivators for the use of agate. The study of different techniques of surface design help to transform this raw material in order it will have the format of a module.
\end{abstract}

Keywords: modular pattern, agate, waterjet machining. 


\section{INTRODUÇÃO}

A presente pesquisa foi planejada com três pilares de sustentação: a aplicação do design de superfície direcionado para o desenvolvimento de uma superfície táctil a partir de um padrão modular encaixável; a valorização de minerais encontrados no Rio Grande do Sul e a utilização de um processo de fabricação inovador.

Alguns dos fatores que motivaram o início deste estudo foram a grande variedade de mineiras encontrados no Rio Grande do Sul e o volume de rejeitos gerados pelas indústrias e fábricas beneficiadoras. O Estado é produtor de uma série de matérias primas com valor comercial. Muitas delas são exportadas em estado bruto, com baixo valor agregado, enquanto outras são parcialmente beneficiadas nas suas cidades e municípios de origem, os quais geram uma grande quantidade de rejeitos descartados como subprodutos.

A ágata utilizada nesta pesquisa, foi doada pela empresa Lodi Pedras Preciosas, localizada no município de Soledade, região conhecida por concentrar as principais empresas de beneficiamento e comércio de materiais gemológicos explorados no estado, e são provenientes de excedentes industriais da sua produção.

Estes resíduos de ágata possuem espessuras variadas, uma vez que provêm de rejeitos industriais vindos das mais diversas aplicações. Quando esta matéria prima foi transformada em pequenas partes modulares, que se encaixaram umas às outras, as variadas espessuras postas lado a lado formaram uma superfície com diferentes níveis. Característica esta que justifica o emprego da expressão táctil, uma vez que táctil se refere a tudo àquilo em que o tacto se pode exercer, ou seja, permitir detectar os altos e baixos relevos através do toque com os dedos.

De outro lado está o design de superfície, área do design que permite o desenvolvimento de atributos estéticos, funcionais e estruturais direcionados para o tratamento de superfícies. Aqui, o design de superfície exerceu um papel importante no beneficiamento do material, pois foi através dele que foi executado o padrão modular encaixável, o qual tomou forma física a partir do material selecionado.

O padrão foi definido por meio de estudos das diferentes técnicas utilizadas pelo artista Maurits Cornelis Escher, justamente pelo fato de encontrar em suas obras uma fonte de referência ideal para a proposta da pesquisa. Neste sentido, um de seus desenhos foi selecionado e aplicado no material escolhido.

Por fim, o terceiro pilar que viabilizou a construção desta pesquisa, foi o processo de fabricação. O processo de fabricação utilizado (jato de água) foi de vital importância para a execução prática deste trabalho, porque possibilitou as devidas interferências no material até que o mesmo tomasse a forma modular de encaixe, conforme o pré-estabelecido na etapa de planejamento da superfície.

Houve a preocupação com a otimização do processo em função da execução em menor tempo, mas também com a obtenção de um bom acabamento final do material e à viabilidade produtiva em baixa escala.

O equipamento de tecnologia por jato de água esteve disponível para a realização da pesquisa no Centro Tecnológico de Pedras, Gemas e Joias do Rio Grande do Sul - CTPedras, localizado em Soledade ${ }^{1}$.

\footnotetext{
Protocolo de cooperação entre UFRGS, UPF, Município de Soledade e Sindipedras assinado em Março de 2010, o qual prevê o apoio das universidades por meio das atividades de ensino-pesquisaextensão para com os setores produtivos da sociedade.
} 


\section{MAURITS CORNELIS ESCHER}

Nesta pesquisa, Escher é tomado como referência não só quanto à autenticidade de suas técnicas, mas também como inspiração. Diante de uma carreira de mais de 50 anos, pode-se dizer que Escher teve quatro grandes períodos. Aqui será particularmente destacado o Período dos ladrilhamentos e metamorfoses (1937 1945), por se tratar do período de maior interesse desta pesquisa, que são as possibilidades de modularidade e encaixe.

A arte do ladrilhamento, ou preenchimento regular da superfície, consiste no preenchimento do plano sem superposição ou buracos. O ladrilhamento era considerado por Escher a técnica ideal, pois, teoricamente, um padrão de ladrilhagem poderia ser estendido indefinidamente, tanto no espaço quanto no tempo. Sua primeira ladrilhagem importante foi Oito cabeças, de 1922, onde um padrão de oito cabeças diferentes encaixa-se uns aos outros, e se repetem quatro vezes (TJABBES, 2011). A figura 1 mostra as formas básicas que passaram a ser usadas por Escher: paralelogramo, retângulo, quadrado, triângulo, losango e hexágono na seqüência.

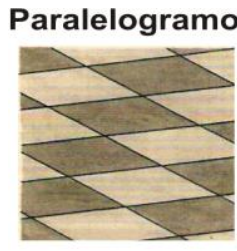

Triângulo

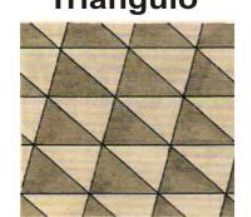

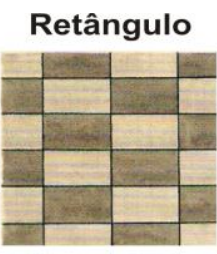

Losango

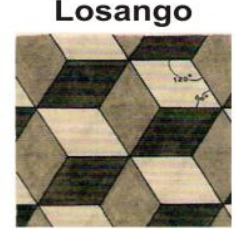

Quadrado

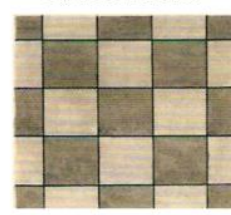

Hexágono

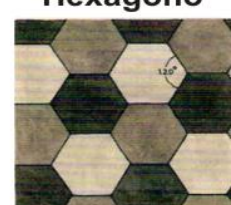

Figura 1 - Formas fundamentais de divisão regular do plano. Fonte: Adaptado de Tjabbes, 2011.

Os sistemas de repetição utilizados por Escher são: translação, reflexão e rotação. No sistema de translação o módulo mantém sua direção original e desloca-se sobre um eixo; na rotação o módulo faz o deslocamento radial ao redor de um ponto; e na reflexão o módulo faz o espelhamento em relação a um eixo (TJABBES, 2011).

A figura 2 mostra estudos de Escher que apontam cinco exemplos de sistemas de repetição a partir da forma quadrada. No exemplo que segue a letra $A$, é utilizado o sistema de translação; na letra $B$, rotação; na letra $C$, translação e rotação; na letra $D$, translação e reflexão; por fim, na letra E, translação, rotação e reflexão.
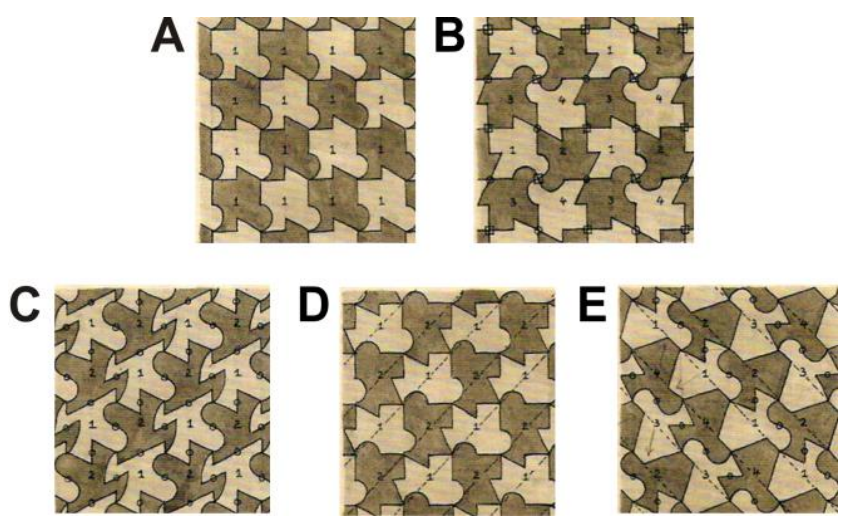

Figura 2 - Cinco exemplos de sistemas baseados no quadrado. Fonte: Adaptado de Tjabbes, 2011. 
Escher continuou a aperfeiçoar sua maestria sobre os ladrilhamentos, cujas possibilidades geométricas ele investigou com maior acuidade entre os anos de 1937 a 1945. Uma característica especial, e pode-se dizer única, da técnica da divisão das superfícies utilizada por Escher, é que ele desenvolvia motivos figurativos. A partir das formas fundamentais citadas, o artista gerou diversos desenhos, principalmente figuras concretas e existentes na natureza, como aves, répteis e figuras humanas.

Vale destacar que, muitos desenhos de Escher já foram utilizados para revestir superfícies de objetos e estampar produtos. A obra Intersecção de dois planos (figura 3) mostra, em formato de desenho gráfico, aproximadamente o que se deseja realizar nesta pesquisa em formato físico. Esta obra é descrita da seguinte maneira: duas pranchas retangulares, finas, planas, intersectam-se uma à outra em ângulo agudo. Em cada prancha estão serrados "buracos" que, como as partes restantes, são em forma de peixes e aves. Os "buracos" de uma prancha podem ser preenchidos com as partes restantes da outra (ESCHER, 1994).

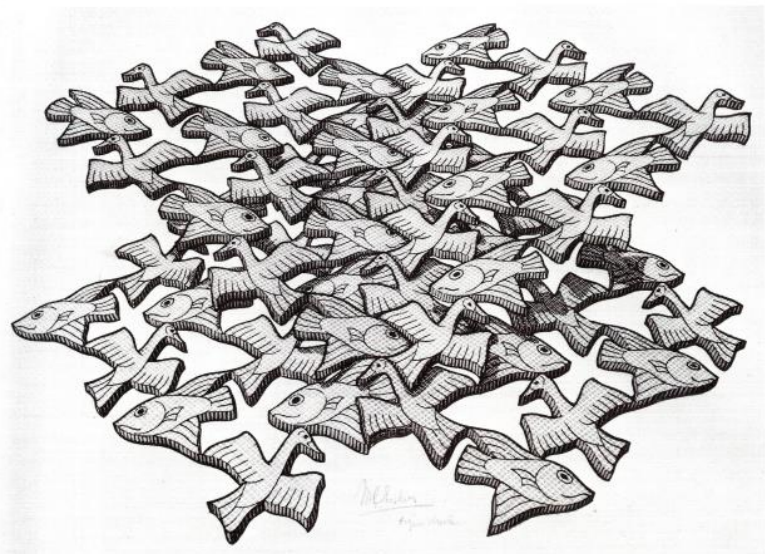

Figura 3 - Intersecção de dois planos em xilografia de 1952. Fonte: Escher, 1994.

Nesta perspectiva, foi selecionado um desenho de Escher, como mostra a figura 4. O desenho será chamado aqui de cavalo alado, por se tratar da figura de um cavalo com asas.

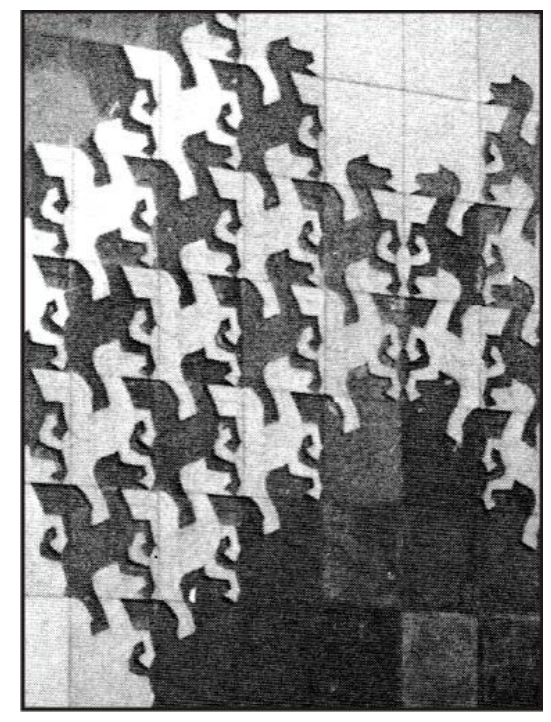


Figura 4 - Cavalo alado. Fonte: Adaptado de Locher, 1988.

O desenho selecionado apresenta um alto nível de complexidade de encaixe uma vez que explora diferentes ângulos e formas. Além disso, o projeto se torna ainda mais complexo quando o objetivo é a criação de uma superfície a partir de um módulo figurativo, ou seja, que representa um elemento já conhecido, pois neste caso, apenas uma linha posta sem precisão, pode descaracterizar a forma e, conseqüentemente, a figura que se deseja transmitir.

\section{3. ÁGATA}

Grande parte dos estados brasileiros produzem algum tipo de material gemológico. Estes materiais se destacam por uma série de motivos, principalmente pela qualidade, variedade, dimensões dos minerais e extensão territorial das áreas de ocorrência. É neste contexto que o Brasil é (re)conhecido como uma das maiores Províncias Gemológicas do planeta (SVISERO \& FRANCO, 1991).

Tratando-se das áreas de produção de gemas no Brasil, pode-se dizer que as regiões nordeste, sudeste e sul possuem um maior número de ocorrências de gemas se comparadas às regiões norte e centro-oeste (IBGM, 2001). Além disso, a região sul do Brasil é considerada um dos maiores polos de extração mineral do país. As ocorrências de ametista e ágata apontam em maior quantidade para o Rio Grande do Sul se comparadas aos outros estados.

O Rio Grande do Sul é um Estado gerador de grande variedade de recursos naturais, os quais possuem valor comercial. Faz-se necessário conhecer o potencial destas riquezas, com o objetivo de contribuir com o Estado em termos econômicos e sociais, visando diferentes possibilidades de utilização destas matérias primas (MAINIERI \& CHIMELO, 1989).

A ágata é a segunda gema de maior ocorrência no Rio Grande do Sul, ficando atrás apenas da ametista. Os produtos desenvolvidos pelas empresas do Rio Grande do Sul que trabalham com ágata, de forma geral, apresentam baixo grau de inovação e design (BARP, 2009).

As pesquisas em design direcionadas ao seu beneficiamento são escassas, deixando em aberto inúmeros pontos a serem aprofundados (TESSMANN, 2009). Com base nesta afirmativa, no contexto geográfico, e na importância deste mineral em termos econômicos e regionais, optou-se por trabalhar com o beneficiamento da ágata, especialmente os rejeitos descartados em chapas, por ser o tipo de corte mais utilizado pelas fábricas da região.

A empresa Lodi Pedras Preciosas (http://www.lodipedras.com.br) foi fundada em 1 de agosto de 1973 em Soledade - RS, e atua no ramo de indústria e comércio de minerais. Os principais minerais trabalhados pela empresa são ágata, ametista e cristal de rocha. A ágata é extraída dos municípios de Soledade e Salto do Jacuí. Os processos produtivos que a empresa possui incluem tais etapas: a extração ou compra de matéria prima, o corte, a lapidação, a martelação, o desenvolvimento de artesanato, artefatos de baixa complexidade e, por fim, a comercialização (COSTA, 2007).

Entre os objetos produzidos estão: porta-copos, objetos decorativos, chaveiros, porta-talheres, entre outros. Esta área necessita de maior nível de aprimoramento, devido à baixa produtividade e qualidade questionável (COSTENARO, 2005). 
Os processos produtivos descritos anteriormente geram resíduos sólidos. A quantidade de resíduos produzidos em uma empresa já pode ser considerada um desafio, o que dirá se levarmos em consideração que hoje o município de Soledade conta com dezenas de empresas (THOMÉ et al., 2010).

Os resíduos de ágata (letras $A$ e $B$ da figura 5) utilizados para o desenvolvimento desta pesquisa foram doados pela empresa no intuito de gerar novas alternativas para os descartes. Este tipo de rejeito é considerado de pré-consumo, uma vez que foi descartado ainda durante as etapas de produção, por motivos como falhas, trincas, rachaduras, etc.
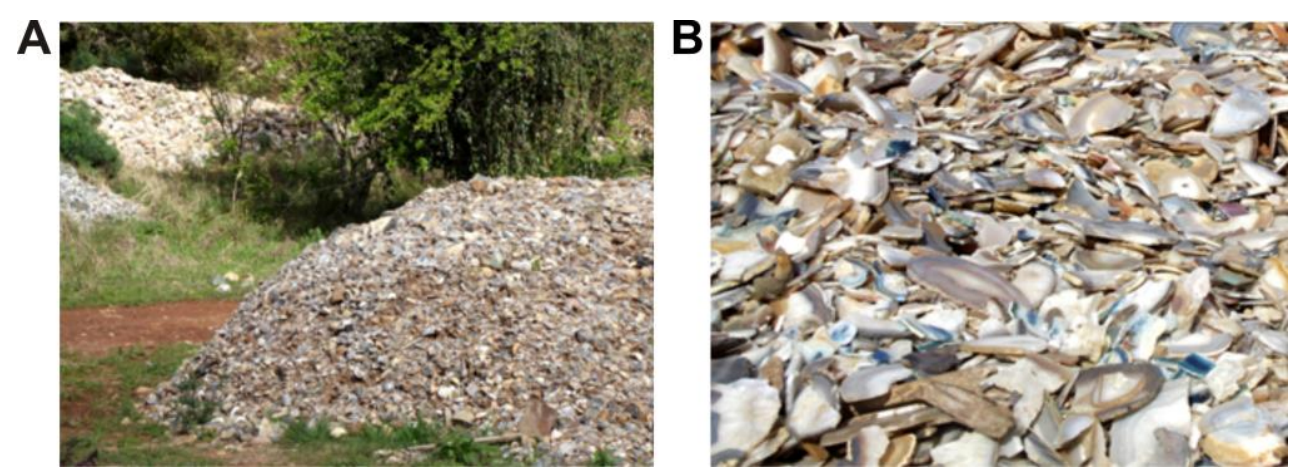

Figura 5 - (A) Resíduos de ágata; (B) Chapas de ágata quebradas.

A inovação, diferenciação, e inserção de novas tecnologias no desenvolvimento dos produtos devem ser amplamente discutidas, pois mesmo com a existência de diferentes empresas, a variedade de produtos é pequena e repetitiva. Além disso, faz com que a ágata, e outros minerais nobres, sejam subutilizados em artefatos comuns, de baixa complexidade, mal valorizados e com altos índices de desperdício. Esta pesquisa propõe-se a valorizar rejeitos deste material através do uso do binômio Design e Tecnologia.

\section{PROCESSO DE FABRICAÇÃO}

O Brasil é produtor de bens minerais para os mercados nacionais e mundiais, e está recentemente ampliando os empreendimentos e diversificando o uso dos minerais que assumem papel de destaque. A característica não renovável dos bens minerais exige avaliação cuidadosa da viabilidade e do aproveitamento econômico do minério. Há que avaliar os prós e contras de cada empreendimento, os efeitos sobre o ambiente e os cuidados necessários, bem como as formas de contribuição para o desenvolvimento econômico (CARVALHO, 2006).

Através deste estudo, pretende-se minimizar o impacto ambiental uma vez que propõe o uso de rejeitos de minerais, e assim gerar um melhor aproveitamento econômico dos materiais naturais. É importante a utilização de novas tecnologias, pois amplia a capacitação empresarial e permite a evolução de testes através do aperfeiçoamento tecnológico.

O processo de fabricação utilizado forneceu uma gama de possibilidades: otimizar o aproveitamento dos materiais através da utilização de ferramentas e equipamentos especiais; primar pela sustentabilidade uma vez que reaproveita materiais de refugo; incorporar a alta tecnologia a um material tradicional e viabilizar a 
capacitação de pessoal qualificado. Desta forma, a pesquisa fez o entrosamento entre setor empresarial e grupos acadêmicos.

\section{USINAGEM POR JATO DE ÁGUA}

Todos os cortes em ágata desta pesquisa foram efetuados através da tecnologia de usinagem por jato de água. Grande parte dos minerais, em especial a ágata, são matérias primas de média a alta dureza e também frágeis, podendo ocasionar fraturas se trabalhados de forma inadequada. Estas características requerem ferramentas e condições especiais para o corte destes materiais.

Neste contexto, optou-se pela tecnologia por jato de água, uma vez que este tipo de maquinário não exige que ferramentas entrem em contato com o material. A tecnologia é de alta precisão, o acabamento de corte é de boa qualidade e o material especificado não tem nenhum tipo de impedimento ao contato com a água.

$\mathrm{O}$ equipamento de usinagem por jato de água de marca Jet Tek WaterJet ${ }^{\circledR}$, utilizado nesta pesquisa, encontra-se no Centro Tecnológico de Pedras, Gemas e Joias do Rio Grande do Sul - CTPedras, localizado no município de Soledade.

No processo de corte por jato de água, a água deve encontrar-se misturada a um abrasivo, o qual também é utilizado como ferramenta de corte, sendo direcionado contra a superfície de trabalho. No caso deste equipamento, o abrasivo empregado foi a granada, que possui dureza Mohs entre 6,5 e 7,5 e granulometria de 80 Mesh, que corresponde a grãos com $0,177 \mathrm{~mm}$ de diâmetro. O abrasivo é responsável por $90 \%$ do corte, restando apenas $10 \%$ para a água (GROOVER, 1996). O jato possui em torno de $0,8 \mathrm{~mm}$ de diâmetro. A pressão pode chegar a $400 \mathrm{MPa}$ (megapascal), onde a água é ejetada do bico a uma velocidade que chega a $900 \mathrm{~m} / \mathrm{s}$. A água é pressurizada por uma bomba hidráulica movida a pistão, com uma potência de $40 \mathrm{CV}$ (cavalo-vapor).

Com o uso desta tecnologia, é possível efetuar cortes bidimensionais em uma grande variedade de materiais, incluindo metais, vidros, mármore, porcelanatos, etc. Esta tecnologia também permite a fabricação de formas vazadas e complexas, que não são possíveis de serem fabricadas manualmente e/ou não são economicamente viáveis quando executadas por outros processos (SILVA et al., 2010).

A usinagem por jato de água utilizada para o corte de figuras em ágata pode ser considerada pouco comum, uma vez que há um número restrito de empresas que dispõem desta tecnologia. No âmbito desta pesquisa, além do CTPedras - RS, localizouse apenas três locais que possuem este equipamento no Estado do Rio Grande do Sul. Estas empresas possuem condições hábeis de fabricar o produto sugerido nesta pesquisa - placas de revestimento - com o maquinário disponível em suas instalações.

\section{6. ÁGATA E CORTE POR JATO DE ÁGUA}

A imagem selecionada (cavalo alado) foi escaneada e salva na extensão JPEG., em seguida foi importada para o programa CorelDRAW X $3^{\circ}$. O CorelDRAW ${ }^{\oplus}$ é um software de desenho vetorial bidimensional direcionado para o design gráfico. Através dos recursos disponíveis neste programa o desenho foi vetorizado, e então foi possível obter o módulo criado por Escher. Em seguida, o módulo foi exportado em extensão DWG. para permitir a rotina de usinagem.

As intenções deste ensaio calcaram-se nas questões experimentais desta nova tecnologia proposta, e também no reconhecimento dos diferentes parâmetros utilizados. Este maquinário permitiu utilizar diferentes velocidades ao longo do 
percurso em uma mesma ação, possibilitando aplicar o parâmetro adequado para o corte desejado.

Foram gerados os comandos necessários para executar o corte das peças, fazendo com que a ágata recebesse a interferência da tecnologia, transferindo para o material o desenho escolhido. A tabela 1 aponta os parâmetros utilizados para o corte, com destaque para a terceira e quarta coluna, as quais apontam as diferentes velocidades programadas para curvas e retas.

Tabela 1 - Parâmetros utilizados para o corte por jato de água em ágata.

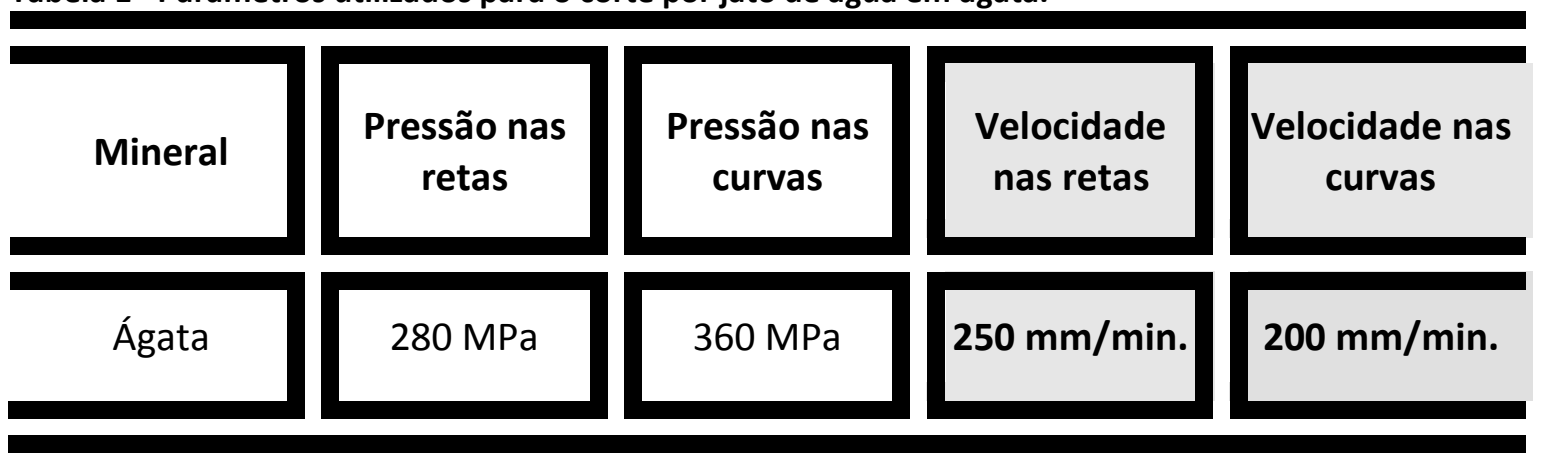

Após o corte foi realizada a revisão das medidas do desenho original e a comparação com as medidas das peças cortadas. Para tanto, foram executadas: digitalização da face superior de todas as peças cortadas e comparação com o desenho original; seleção de uma peça para a digitalização tridimensional completa, com revisão de detalhes e, por fim, avaliação dos níveis de alteração entre a digitalização tridimensional completa e o desenho original.

Nesta perspectiva, o ensaio foi executado a partir do módulo com dimensões de: $48,4 \times 50 \times 6 \mathrm{~mm}$ (LXAXP). A figura 6 mostra as peças após o corte e a superfície formada. Verificou-se que foi possível efetuar o encaixe dos módulos, no entanto, as peças ainda apresentaram uma pequena folga entre um e outro encaixe.

Esta folga ocorre devido à perda de material quando do corte, ou seja, a peça final não é fidedigna ao desenho original uma vez que a perda de material diminui as medidas, e conseqüentemente, a proporção total da peça.

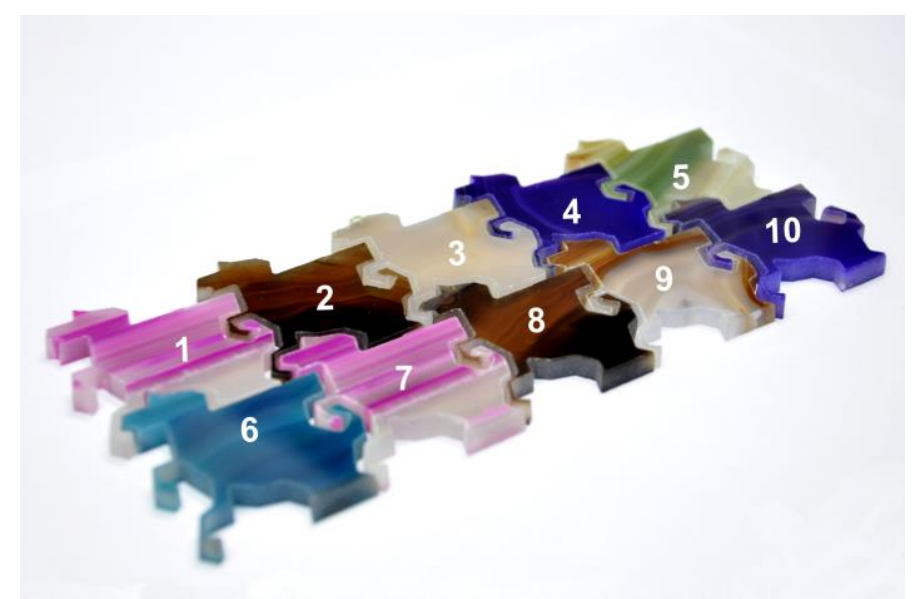

Figura 6 - Encaixe dos módulos (cavalo alado). 
A seqüência adotada para a medição seguiu a numeração da figura 6, e as medidas avaliadas foram largura e altura. Para esta análise, foi desconsiderada a profundidade ou a espessura das peças, uma vez que esta medida não se modifica em relação ao corte. $O$ instrumento utilizado para a medição foi o paquímetro de precisão da marca Mitutoyo.

A medição foi feita em todas as peças. Em seguida, foi feito uma média da largura e altura de todas elas. Verificou-se que a média da largura de todas as peças conferiu o valor de $46,3 \mathrm{~mm}$, e a média da altura de todas as peças conferiu o valor de $47,9 \mathrm{~mm}$. Foi detectada uma pequena variação tanto de largura quanto de altura entre uma peça e outra, no entanto a média final aponta o resultado geral da medição.

Tendo em vista que as medidas de largura e altura do desenho original são $48,4 \times 50 \mathrm{~mm}$, e que a média destas medidas das peças cortadas são 46,3×47,9 mm, concluiu-se que a perda de material foi em média de $2,1 \mathrm{~mm}$ na largura e na altura.

Para verificar se a perda de material ocorreu uniformemente em toda borda da peça, ou se houve menor ou maior perda dependendo da região do corte, a face superior de todas as peças foi digitalizada no scanner 3D Digimill $^{\circledR}$ do fabricante Tecnodrill localizado no LdSM com o objetivo de compará-las ao arquivo original.

Após o processo de digitalização, as informações do escaneamento, também chamadas de malha de pontos, foram visualizadas no software Geomagic Qualify ${ }^{\oplus}$ do fabricante Geomagic Labs ${ }^{\circledR}$, especializado na criação de modelos 3D.

Em seguida, o arquivo foi exportado em extensão IGES., a qual é compatível com o software Rhinoceros $3 \mathrm{D}^{\oplus}$ do fabricante Robert McNeel \& Associates. O Rhino $3 \mathrm{D}^{\oplus}$ fornece ferramentas para modelar desenhos com precisão, preparando-os para renderização, análise, engenharia, fabricação ou construção. Neste software os dados foram projetados em um plano e o arquivo foi salvo em extensão DWG., a qual é compatível com o CorelDRAW X $3^{\circledR}$, software utilizado na seqüência dos testes. A figura 7 mostra, em formato vetor, a digitalização da face superior de todas as peças. Os caminhos em branco entre as peças são as folgas que não existiam no desenho original.

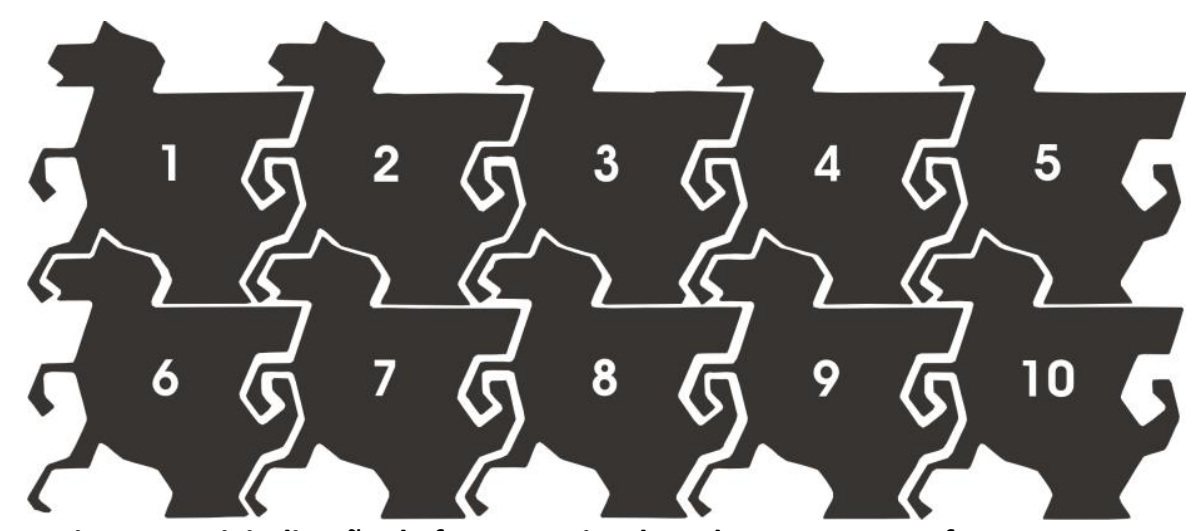

Figura 7 - Digitalização da face superior de todas as peças em formato vetor.

A digitalização da face superior da peça 1 foi sobreposta ao desenho original (letra A da figura 8). Em determinados segmentos na extensão da borda há maior perda de material, em contrapartida, em outros segmentos há menor perda, como mostra a sobreposição na letra B da figura 8. Este aspecto foi revisto de forma mais 
precisa na seqüência de testes. O mesmo procedimento comparativo foi realizado com o restante das faces digitalizadas, as quais apresentaram o mesmo comportamento.

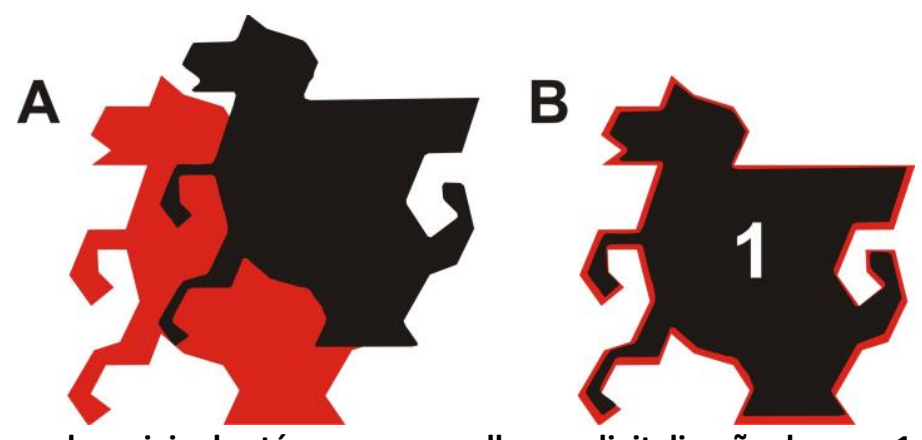

Figura 8 - (A) 0 desenho original está na cor vermelha e a digitalização da peça 1 está na cor preta; (B) Na sobreposição a borda em vermelho equivale à perda de material.

Em vista de todas as peças terem apresentado comportamento similar de variação, julgou-se necessário selecionar apenas uma peça para passar pelo processo de digitalização completa, incluindo todas as faces, não somente a face superior. A digitalização completa permitiu calcular o volume de material perdido; avaliar detalhes com maior precisão; e detectar os segmentos de maior e menor perda de material.

Nesta perspectiva, a letra A da figura 9 mostra a digitalização completa da peça 1 e, novamente, a sobreposição da mesma com o desenho original através do software Studio ${ }^{\circledR}$. Através desta simulação verificou-se o volume tanto do desenho original quanto da peça cortada. O desenho original apresentou volume de $8.242 \mathrm{~mm}^{3}$, já a peça cortada - no caso deste exemplo a peça 1 - apresentou volume de $6.850 \mathrm{~mm}^{3}$. Conclui-se que ocorreu uma perda de $1.392 \mathrm{~mm}^{3}$, isto equivale a $16,89 \%$ do material. Além disso, através do detalhe destacado pelo círculo vermelho (letra B da figura 9) notou-se que os cantos vivos, ou muito angulosos, têm a tendência a ser sutilmente arredondados durante o corte, o que, neste caso, não prejudica os encaixes.

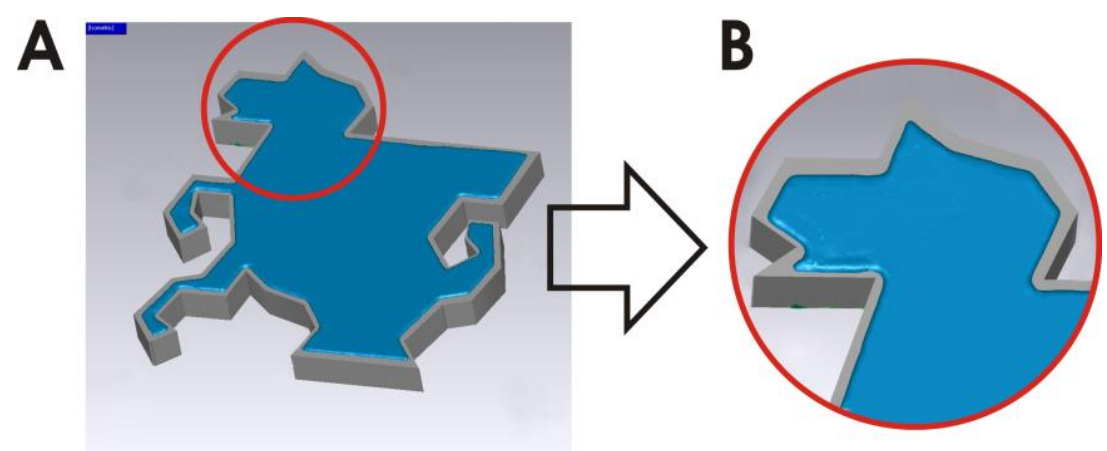

Figura 9 - (A) $O$ desenho original encontra-se na cor cinza e a digitalização da peça 1 encontra-se na cor azul; (B) Detalhe.

A letra A da figura 10 mostra, através de uma legenda de cores, os níveis de alteração entre a peça cortada e o desenho original. O local preenchido pela cor verde mostra a área na qual a peça cortada coincidiu com a área do desenho original, ou seja, a maior parte da peça. As cores mostradas na legenda acima da cor verde - do amarelo ao vermelho - detectam no desenho tridimensional as áreas que a peça cortada ficou acima do desenho original. Neste caso apenas alguns pontos amarelos 
isolados, que não demonstram importância significativa. Já as cores mostradas na legenda abaixo da cor verde, que vai desde o azul claro até o azul escuro, detectam no desenho as áreas que a peça cortada ficou abaixo do desenho original, ou seja, onde ocorreu a perda de material. Estas são as áreas de maior interesse nesta avaliação.

Como já detectado anteriormente, toda a borda da peça apresentou perda de material, no entanto, pode-se confirmar que a perda não é uniforme em toda lateral.

Através do detalhe destacado pelo círculo vermelho (letra $B$ da figura 10) notase que o desgaste lateral, quando próximo à face superior da peça, detecta a cor azul escuro. Quanto mais próximo à face inferior da peça, o desgaste passa a detectar tons de azuis claros. Quando a cor azul escuro é detectada, significa que nesta área a perda de material foi de $1,05 \mathrm{~mm}$, como mostra a numeração ao lado da legenda. Quando a cor azul claro é detectada, significa que nesta área o desgaste foi de $0,14 \mathrm{~mm}$.

Se levarmos em consideração que o lado direito analisado desgastou $1,05 \mathrm{~mm}$ próximo à face superior, e que o lado esquerdo da mesma forma também desgastou $1,05 \mathrm{~mm}$ próximo à face superior, conclui-se que o desgaste total na largura da peça próximo à face superior é de $2,1 \mathrm{~mm}$, exatamente como verificado anteriormente. Isto também vale para a medida da altura.

No entanto, o lado direito analisado desgastou $0,14 \mathrm{~mm}$ próximo à face inferior, e o lado esquerdo da mesma maneira também desgastou $0,14 \mathrm{~mm}$ próximo à face inferior, conclui-se que o desgaste total na largura da peça próximo à face inferior é de $0,28 \mathrm{~mm}$. Através destes dados, conclui-se que o corte por jato de água tende a retirar mais o material quando do início do corte $(2,1 \mathrm{~mm})$, ou seja, próximo à face superior e tende a retirar menos o material quando do fim do corte $(0,28 \mathrm{~mm})$, ou seja, próximo à face inferior. Estes resultados permitem que os arquivos gerados para o corte das peças direcionadas para o produto final sejam adaptados.
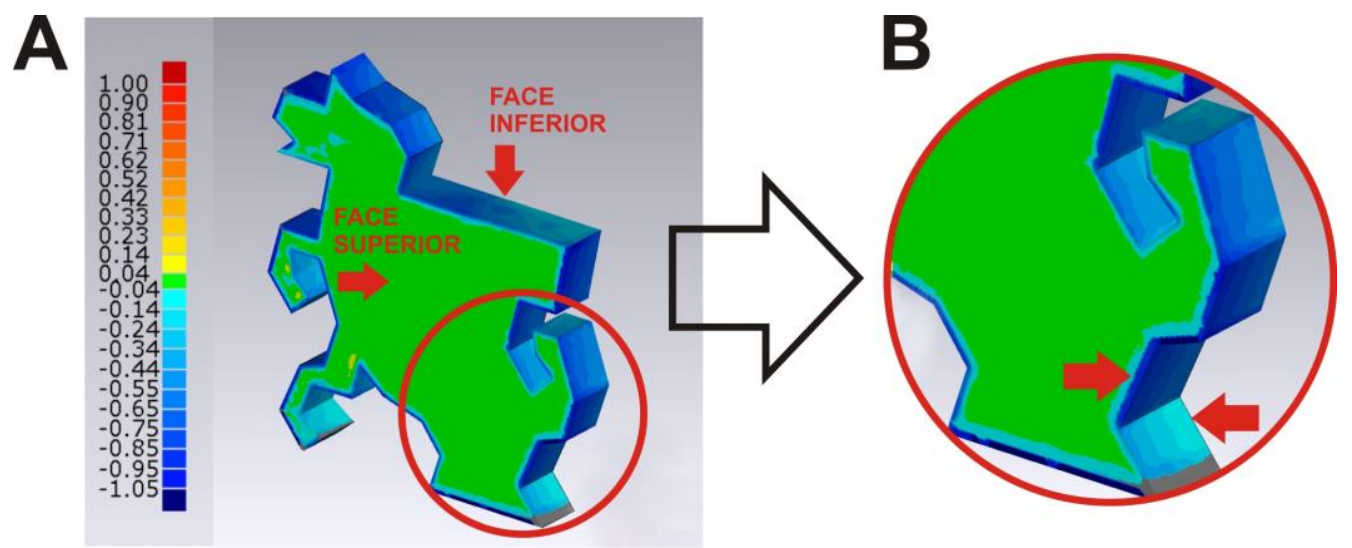

Figura 10 - (A) Níveis de alteração entre a peça cortada e o desenho original através de legenda de cores; (B) Detalhe.

\section{CONCLUSÃO}

Os testes práticos efetuados em ágata possibilitaram a aproximação do design de superfície com a tecnologia por jato de água. Também se fez reconhecer os diferentes parâmetros adotados para o corte que, neste caso, estão relacionados às variações de pressão e velocidade nas curvas e retas. Além disso, a principal característica desta tecnologia quando em contato com a ágata, é a perda de material, a qual foi analisada de forma minuciosa durante os testes. Os resultados permitem que os arquivos gerados para o corte das peças direcionadas para o produto final - painéis 
de revestimento - sejam adaptados. É possível efetuar a alteração das proporções do arquivo original prevendo a perda de material, diminuir o risco de erro e aperfeiçoar o encaixe das peças para o desenvolvimento de paineis tácteis a partir de um padrão modular encaixável, como mostra o resultado final desta pesquisa na figura 11.

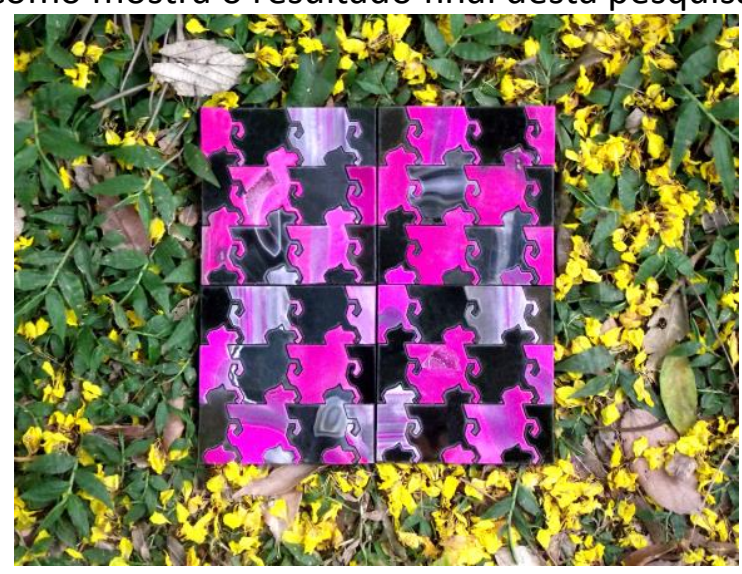

Figura 11 - Painel de revestimento.

\section{AGRADECIMENTOS}

Este trabalho foi realizado com o apoio do CNPq. Também foi de vital importância o apoio do Laboratório de Design e Seleção de Materiais - LdSM. Assim como do Centro Tecnológico de Pedras, Gemas e Joias do Rio Grande do Sul - CTPedras e da empresa Lodi Pedras Preciosas.

\section{REFERÊNCIAS}

BARP, D. R. A. Design e materiais: contribuição ao estudo do processo de corte de ágata por jato d'água em formas complexas. 2009. Dissertação (Mestrado em Design) - Universidade Federal do Rio Grande do Sul, Porto Alegre.

CARVALHO, C. A. A. 3ํ Conferência Nacional de Ciência, Tecnologia e Inovação: síntese das conclusões e recomendações. Brasília: Ministério da Ciência e Tecnologia, Centro de Gestão de Estudos Estratégicos, 2006.

COSTA, M. Beneficiamento de Pedras Preciosas no Vale do Taquari - Diagnóstico e Modelo para Análise e Redução de Perdas nos Processos Produtivos. 2007. Dissertação. Programa de Pós-Graduação em Engenharia de Produção. Universidade Federal do Rio Grande do Sul. Porto Alegre, 2007.

COSTENARO, A. Indústrias de Pedras Preciosas: um estudo dos fatores competitivos em empresas de Soledade-RS. 2005. Dissertação. Programa de Pós Graduação em Administração, Universidade Federal de Santa Maria. Santa Maria, 2005.

ESCHER, M. C. Gravura e desenhos. Koln: Taschen, 1994.

GROOVER, M. P. Fundamentals of modern manufacturing: materials, processes, and systems. Englewood Cliffs: Prentic Hall, 1996.

Instituto Brasileiro de Gemas e Metais Preciosos (IBGM). Departamento Nacional de Produção Mineral (DNPM). Manual técnico de Gemas. Brasília, 2001.

LOCHER, J. L. The world of M. C. Escher. Nova lorque: Harry N. Abrams, 1988. 
Lodi Pedras Preciosas. Disponível em: http://www.lodipedras.com.br. Acessado em: 05 de novembro de 2011.

MAINIERI, C; CHIMELO, P. C. Ficha de características das madeiras brasileiras. São Paulo: Instituto de pesquisas tecnológicas (IPT), 1989.

SILVA, J. T; HARTMANN, L. A; HAUSCHILD, C. A. O centro tecnológico de pedras, gemas e jóias do Rio Grande do Sul no ambiente de um arranjo produtivo local. HARTMANN, L. A; SILVA, J. T. Tecnologias para o setor de gemas, joias e mineração. Porto Alegre: IGEO/UFRGS, 2010.

SVISERO, D. P.; FRANCO, R. R. A província gemológica brasileira. In: Principais depósitos minerais do Brasil. DNPM, 1991.

TESSMANN, C. S. Importância do binômio design e engenharia no beneficiamento de rejeitos minerais de opala e ágata na produção de camafeus por usinagem CNC. 2009. Dissertação (Mestrado em Design) - Universidade Federal do Rio Grande do Sul, Porto Alegre.

THOMÉ, A; ABREU, A. G; BRANDLI, L. L; FERNANDES, V. M. C; PRIETTO, P. D. M. Diagnóstico dos resíduos gerados pelo setor de pedras preciosas do município de Soledade/RS. 